\title{
Optimization of phenolic compounds extraction with antioxidant activity from açaí, blueberry and goji berry using response surface methodology
}

\author{
Cristiane de Moura', Amália Soares dos Reis'1, Letícia Dangui da Silva1', Vanderlei Aparecido de Lima', \\ Tatiane Luiza Cadorin Oldoni ${ }^{1}$, Celeide Pereira ${ }^{2}$, Solange Teresinha Carpes ${ }^{1 *}$ \\ ${ }^{1}$ Department of Chemistry, Federal Technological University of Paraná (UTFPR), Pato Branco, PR, Brazil, ${ }^{2}$ Department of Food, Federal \\ Technological University of Paraná (UTFPR), Medianeira, PR, Brazil
}

\section{A B S TR A C T}

\begin{abstract}
The aim of this study was to determine the best extraction conditions of phenolic compounds present in açaí, blueberry and goji berry fruits using the response surface methodology (RSM). The phenolic compounds profile by high-performance liquid chromatography, antioxidant activity was also determined. A factorial $2^{3}$ design was used to analyze the effect of the solvent (ethanol and water), time (30 and 60 min) and temperature $\left(30^{\circ} \mathrm{C}\right.$ and $60^{\circ} \mathrm{C}$ ) on the extraction of total phenolic compounds (TPC) and activity antioxidant (AA). The variables time and temperature had a positive effect on antioxidant activity (AA) in their highest levels, 60 min and $60{ }^{\circ} \mathrm{C}$, respectively. The solvent ethanol $800 \mathrm{~g} / \mathrm{mL}$ was more efficient in TPC extracting with AA in all matrices. Rutin was present in high amounts in blueberry and goji berry, and the myricetin in açaí. The açaí showed higher in vitro antioxidant activity when extracted at $60{ }^{\circ} \mathrm{C}$ for 60 min. The high correlation coefficient (0.98) of global response (GR) showed that we can find out single and global response in research with multiple dependent variables. The GR analysis indicated the highest values of the TPC and AA when the fruits were extracted at $60^{\circ} \mathrm{C}$ for 60 min using ethanol as solvent and it was very useful for simplifying and improving the phenolic compounds extraction performance.
\end{abstract}

Keywords: Antioxidant activity; Extraction conditions; Factorial design; HPLC/DAD; Phenolic compounds

\section{INTRODUCTION}

The food function goes beyond only nurture (Moraes et al., 2007; Kang et al., 2012; Silva et al., 2014), but may also be related to disease prevention (Castrejón et al., 2008; Paz et al., 2015), leading the consumer to increasingly opt for healthier foods (Swieca, 2015). Fruits can be natural sources of antioxidants such as vitamins (Oliveira et al., 2011; Leong and Oey, 2012), carotenoids (Souza et al., 2014; Valdivielso et al., 2015) and phenolic compounds (Kang et al., 2012; Paz et al., 2015) with antioxidant properties (Castrejón et al., 2008; Koca and Karadeniz, 2009; Kang et al., 2012). The antioxidant activity of these compounds may act at different stages in the oxidation process, lowering free radicals concentration, chelating ions and even decomposing primary products and leading to nonradical compounds (Lobo et al., 2010; Perera et al., 2016) which help balance the immune system (Kang et al., 2012).
Açaí and blueberry stand out mainly for the presence of red pigments called anthocyanin (Su and Chien, 2007, Kang et al., 2011, Rodrigues et al., 2011; Gordon et al., 2012). In addition to anthocyanins, blueberry is an excellent source of quercetin, kaempferol, myricetin, procyanidins, catechin, epicatechin, resveratrol and vitamin $\mathrm{C}$, which contribute to antioxidant activity and bring health benefits to people (Rodrigues et al., 2011; Norberto et al., 2013). The Amazon açaí is widely consumed in Brazil but is already part of the eating habits of vast majority of the world's population. Its fruit exhibit pharmacological and medicinal properties mainly anticarcinogenic (Choi et al., 2017; Wang et al., 2016), anti-inflammatory (Favacho et al., 2011; Kang et al., 2011) Kang et al. (2012) and antimicrobial (Shen et al., 2014; Belda-Galbis et al., 2015) activities. Amazon açaí, in addition to its nutritional qualities, is of great importance for the development of the Amazon region (Gordon et al., 2012).

\footnotetext{
*Corresponding author:

Solange Teresinha Carpes, Department of Chemistry, Federal Technological University of Paraná (UTFPR), Pato Branco, PR, Brazil.

E-mail: carpes@utfpr.edu.br
} 
Goji berry, a fruit originated from Asian countries such as China and India, has been used for many years in herbal medicine (Carnés et al., 2013; Donno et al., 2015). This fruit is considered a functional food of great importance for the China and has become increasingly common in the Europe and North America (Li et al., 2007, Dong et al., 2009; Carnés et al., 2013). Goji berry has gained prominence in recent years in the scientific community due to its anti-inflammatory (Potterat, 2010; Nardi et al., 2016), antioxidant (Amagase and Farnsworth, 2011; Donno et al., 2015) and antitumor (Wawruszak et al., 2016) activities. In addition, the Gojy berry may be effective in prophylaxis of diseases, such as diabetes, and cardiovascular diseases (Kulczyński and Gramza-Michałowska, 2016).

Given the economic and nutritional importance of these species, some studies regarding the extraction process and optimization of extraction conditions are necessary. Obtaining biologically active compounds involves many factors and the experimental design is an adequate methodology to experimentation, which allows the reduction in the number of the tests without prejudice to the quality of the information. Thus, the objective of this study was to investigate the influence of different factors (time, temperature and nature of solvent) on phenolic compounds extraction present in açaí, blueberry and goji berry fruits, through RSM. The chromatographic profile analysis and antioxidant activity of the best extract condition were aim of this work, too.

\section{MATERIAL AND METHODS}

\section{Samples}

Samples of açaí, blueberry and goji berry were obtained in the Municipal Market of Curitiba - Paraná, Brazil. The fruits were lyophilized (Liotop - L1019, São Paulo, Brazil) and ground in an analytical mill and stored at $-12^{\circ} \mathrm{C}$.

\section{Preparation of extract and experimental design}

The $2^{3}$ factorial design was used to evaluate the effect of solvent, temperature and time over phenolic compounds extraction. The design was composed of eight trials performed in triplicate. Independent variables were: ethanol $800 \mathrm{~g} / \mathrm{L}$ and pure water as solvent (variable X1), extraction time of $30 \mathrm{~min}$ and $60 \mathrm{~min}$ (variable $\mathrm{X} 2$ ), and extraction temperature of $30^{\circ} \mathrm{C}$ and $60^{\circ} \mathrm{C}$ (X3 variable) while dependent variables were antioxidant activity (AA) and total phenolic compounds (TPC).

The extraction of antioxidant compounds were performed according to Ribeiro et al. (2007). Samples containing $3 \mathrm{~g}$ of lyophilized fruits were subjected to the extraction process with $30 \mathrm{~mL}$ of solvent in a shaker (Solab SL222,
Piracicaba, Brazil) according to the experimental design shown in Table 1. The extracts were transferred to Falcon tube and centrifuged at $447 \mathrm{x} g$ for $15 \mathrm{~min}$ (Hermle Z 200 A, Wehingen, Germany). After filtrating, the supernatants were stored in a freezer at $-12{ }^{\circ} \mathrm{C}$. Each extraction was performed in triplicate amounting to 24 trials for each fruit.

\section{Total phenolic compounds assay}

Total phenolic compounds (TPC) were quantified by the Folin-Ciocalteu method described by Singleton et al. (1999) using gallic acid as the standard.

\section{Anthocyanin assay}

Total anthocyanin content (TAC) was determined using the pH-differential method (Giusti and Wrolsted, 2001).

\section{Antioxidant activities}

Four methods were used to determine the antioxidant capacity of the samples: DPPH (2,2-diphenyl-1-picrylhydrazyl) radical scavenging, ABTS (2,2'-Azino-bis (3-ethylbenzthiazoline-6-sulphonic acid)), coupled oxidation of $\beta$-carotene and linoleic acid and ferric reducing antioxidant power (FRAP).

\section{$D P P H$ radical scavenging assay}

Measurement of DPPH scavenging activity was performed according to the methodology described by Brand-Williams et al. (1995). The results were expressed as $\mathrm{EC}_{50}$ (concentration required to obtain a 50\% antioxidant effect) and $\mu \mathrm{mol}$ Trolox/g sample. Absorbances were read in spectrophotometer (Bel Photonics 2000, Piracicaba, Brazil) at $517 \mathrm{~nm}$ and the tests were performed in triplicate.

\section{ABTS 12,2'-Azino-bis 13-ethylbenzthiazoline-6- sulphonic acid)l assay}

The antioxidant activity by the ABTS method was performed according to Re et al. (1999), in UV/Vis spectrophotometer (Bel Photonics 2000, Piracicaba, Brazil) at $734 \mathrm{~nm}$. Trolox was used as reference and the results of the antioxidant activity were expressed as $\mu \mathrm{mol}$ of trolox equivalent antioxidant capacity (TEAC)/g of sample. All analyses were carried out in triplicate.

\section{Coupled oxidation of $\beta$-carotene and linoleic acid assay}

The measure of antioxidant activity was determined by the coupled oxidation of $\beta$-carotene and linoleic acid according to Ahn et al. (2004). Emulsion oxidation was spectrometrically monitored (Bel Photonics 2000, Piracicaba, Brazil) and the absorbance was read at $470 \mathrm{~nm}$, at time zero $(t=0)$ and subsequently after every $20 \mathrm{~min}$, until the characteristic color of $\beta$-carotene disappeared in the control reaction $(\mathrm{t}=100 \mathrm{~min})$. The antioxidant 
de Moura, et al.

Table 1: Factor delineation for total phenolic compounds and antioxidant activity in açaí, blueberry and goji berry

\begin{tabular}{|c|c|c|c|c|c|c|c|c|c|}
\hline \multirow[t]{2}{*}{ Assay } & \multirow[t]{2}{*}{$\mathbf{X} 1$} & \multirow[t]{2}{*}{$\mathrm{X} 2$} & \multirow[t]{2}{*}{ X3 } & \multicolumn{2}{|c|}{ Açaí } & \multicolumn{2}{|c|}{ Blueberry } & \multicolumn{2}{|c|}{ Goji berry } \\
\hline & & & & $\begin{array}{c}\text { TPC } \\
\text { (mg } \\
\text { GAE/g) }\end{array}$ & $\begin{array}{c}\text { AA } \\
(\mu \mathrm{mol} \\
\text { Trolox/g) }\end{array}$ & $\begin{array}{c}\text { TPC } \\
\text { (mg } \\
\text { GAE/g) }\end{array}$ & $\begin{array}{c}\text { AA } \\
(\mu \mathrm{mol} \\
\text { Trolox } / g)\end{array}$ & $\begin{array}{c}\text { TPC (mg } \\
\text { GAE/g }\end{array}$ & $\begin{array}{l}\text { AA ( } \mu \text { mol } \\
\text { Trolox/g) }\end{array}$ \\
\hline A1 & Water $(-1)$ & $30(-1)$ & $30(-1)$ & $18.68^{c}$ & $33.93^{\circ}$ & $6.01^{e}$ & $9.18^{c}$ & $15.14^{e}$ & $8.89^{9}$ \\
\hline A2 & Ethanol $(+1)$ & $30(-1)$ & $30(-1)$ & $14.46^{g}$ & $45.73^{d}$ & $13.33^{c}$ & $30.51^{b}$ & $11.77^{\mathrm{g}}$ & $14.40^{d}$ \\
\hline A3 & Water $(-1)$ & $60(+1)$ & $30(-1)$ & $19.02^{b}$ & $31.00^{\mathrm{g}}$ & $6.19^{e}$ & $8.89^{c}$ & $15.74^{c}$ & $9.76^{\mathrm{e}}$ \\
\hline A4 & Ethanol $(+1)$ & $60(+1)$ & $30(-1)$ & $15.55^{f}$ & $52.44^{b}$ & $15.04^{b}$ & $32.96^{b}$ & $15.18^{e}$ & $15.39^{c}$ \\
\hline A5 & Water $(-1)$ & $30(-1)$ & $60(+1)$ & $17.90^{d}$ & $31.87^{f}$ & $6.93^{e}$ & $10.40^{c}$ & $15.49^{d}$ & $9.79^{f}$ \\
\hline A6 & Ethanol $(+1)$ & $30(-1)$ & $60(+1)$ & $15.60^{e}$ & $47.14^{c}$ & $15.76^{b}$ & $32.87^{b}$ & $13.84^{\dagger}$ & $16.29^{b}$ \\
\hline A7 & Water $(-1)$ & $60(+1)$ & $60(+1)$ & $21.31^{a}$ & $27.22^{\mathrm{h}}$ & $8.98^{d}$ & $12.43^{c}$ & $21.62^{\mathrm{a}}$ & $11.86^{e}$ \\
\hline A8 & Ethanol $(+1)$ & $60(+1)$ & $60(+1)$ & $18.69^{c}$ & $57.91^{\mathrm{a}}$ & $17.91^{\mathrm{a}}$ & $49.53^{\mathrm{a}}$ & $16.59^{b}$ & $19.40^{\mathrm{a}}$ \\
\hline $\begin{array}{l}\text { Pooled } \\
\text { SD }\end{array}$ & - & - & - & 2.36 & 10.91 & 4.32 & 13.79 & 2.77 & 3.64 \\
\hline
\end{tabular}

The experiments were performed in duplicate and the results expressed as mean $(n=2)$; Runs: assay A1 to A8 - combination of solvent, time and temperature; variable $\times 1$ : solvent; variable $\times 2$ : temperature $\left({ }^{\circ} \mathrm{C}\right)$; variable $\times 3$ : time $(\mathrm{min})$; Values followed by different letters in the same column are significantly different $(P<0.05)$. TPC: Total phenolic compounds; AA: Antioxidant activity (DPPH method).

activity was determined as percent inhibition relative to control sample.

\section{Ferric reducing antioxidant power (FRAP) assay}

Antioxidant activity determination using the FRAP method was performed as described by Pulido et al. (2000). The absorbance was measured in UV/Vis spectrophotometer (Bel Photonics 2000, Piracicaba, Brazil) at $593 \mathrm{~nm}$. Aqueous solutions of ferrous sulfate were used for calibration, and the results were expressed as $\mu \mathrm{mol}$ of $\mathrm{Fe}^{2+} / \mathrm{g}$ of the sample. All analyses were carried out in triplicate.

\section{HPLC-DAD-UV-Vis profile}

The extracts obtained under optimum conditions as indicated by the factorial design were rotary evaporated (Fisatom ${ }^{\circledR}$ 802, Sao Paulo, Brazil) and lyophilized (Liotop - L1019, São Paulo, Brazil). Aliquots $10 \mu \mathrm{L}$ at $0.1 \mathrm{~g} / \mathrm{mL}$ of extract concentration were injected into a chromatograph coupled to a photodiode array (PDA) detector (Varian, 920-LC, Walnut Creek, US) using a C18 $\mathrm{RP}(250 \times 4,6 \mathrm{~mm}, 5 \mu \mathrm{m})$ column. For the fractionation, a binary gradient system was used in which the mobile phase " $\mathrm{A}$ " consisted of ultrapure water and phase "B" consisted of acetonitrile, both containing $0.2 \mathrm{~mL} / \mathrm{L}$ acetic acid. The gradient started with $5 \%$ of B up to $95 \%$ of B in 36 min and returned to the initial condition. Total analysis time was $45 \mathrm{~min}$ at a flow rate of $1 \mathrm{~mL} / \mathrm{min}$ and the temperature during the analysis was maintained at $30{ }^{\circ} \mathrm{C}$. Calibration curves and linear regression based on the peak areas were used to identify and quantify peaks corresponding to the phenolic compounds. The identification was performed by comparison of retention times and absorption in ultraviolet at wavelengths of $280 \mathrm{~nm}$ and $320 \mathrm{~nm}$. These calibration curves were obtained using external standards of catechin, caffeic acid, ferulic acid, epicatechin, coumaric acid, gallic acid, rutin, and myricetin. All standards were dissolved in phase "B" at the following concentrations:
$2 \mu \mathrm{g} / \mathrm{mL} ; 4 \mu \mathrm{g} / \mathrm{mL} ; 8 \mu \mathrm{g} / \mathrm{mL} ; 16 \mu \mathrm{g} / \mathrm{mL} ; 30 \mu \mathrm{g} / \mathrm{mL}$. These concentrations were used afterwards for obtaining the limit of quantification (LQ) of $0.35 \mu \mathrm{g} / \mathrm{mL}$ and the detection limit (LD) of the equipment of $0.12 \mu \mathrm{g} / \mathrm{mL}$ employing standards of gallic acid, vanillic acid, caffeic acid, coumaric acid, and ferulic acid according to Oldoni et al. (2015). The content phenolic compounds were expressed for each compound in $\mu \mathrm{g} / \mathrm{g}$ of sample. Determination of the phenolic compounds by HPLC was performed in triplicate.

\section{Statistical analysis}

The set of data and contents of total phenolic compounds derived from the factorial design were analyzed by response surface methodology (RSM). The anthocyanin content and the antioxidant activity were carried out by principal component analysis (PCA). The data were processed by one-way analysis of variance (ANOVA). The averages were compared by Tukey test, considering the significance level of $95 \%(p<0.05)$, using the STATISTICA program 8.0 version (StatSoft, USA). Past Software 3.07 developed by Hammer et al. (2001) expressed the reproducibility of the results as Pooled Standard Deviation (Pooled SD). The global response (GR) was carried out over the data set too. GR was calculated according to equation (1):

$$
R G=\left[\frac{R\left(x_{1}\right)}{M R\left(x_{1}\right)}+\frac{R\left(x_{2}\right)}{M R\left(x_{2}\right)}+\ldots+\frac{R\left(x_{n}\right)}{M R\left(x_{n}\right)}\right]
$$

Where: $R\left(x_{n}\right)$ is the response for each dependent variable, $\operatorname{MR}\left(\mathrm{x}_{\mathrm{n}}\right)$ is the maximum value of response for each dependent variable. All experiments were carried out three times.

\section{RESULTS AND DISCUSSION}

Total phenolic compounds (TPC) content and antioxidant activity (AA) in fruit extracts after being subjected to 
various treatments (A1 to A8) according to factorial design are summarized in Table 1. Extracts obtained a specific and characteristic coloring for each fruit, differing according to the solvent extractor. These variations can be caused by the diversity of compounds each solvent can extract. It is depending on their polarity, thus providing different colors for each respective extract.

The total average of TPC content in açaí extracts ranged from 14.46 to $21.31 \mathrm{mg} \mathrm{GAE} / \mathrm{g}$ sample and AA from 27.22 to $57.91 \mu \mathrm{mol}$ of Trolox/g sample. Açaí TPC content in assays $\mathrm{A} 1$ (water, $30^{\circ} \mathrm{C}, 30 \mathrm{~min}$ ) and $\mathrm{A} 8$ (ethanol, $60^{\circ} \mathrm{C}, 60 \mathrm{~min}$ ) did not differ statistically by the Tukey test $(\mathrm{p}<0.05)$. The lower TPC content was found in assay A2 (ethanol, $30^{\circ} \mathrm{C}, 30 \mathrm{~min}$ ) and significantly differ from the others treatments. The greatest TPC content in the açaí samples was found at $\mathrm{A} 7$ treatment (water, $60^{\circ} \mathrm{C}, 60 \mathrm{~min}$ ), but with lower AA (Table 1). In this study, the results of TPC and AA from açaí were lower than those reported by Kang et al. (2012) in açaí from Para State, Brazil. The values ranged from 31.2 to $73.0 \mathrm{mg} \mathrm{GAE} / \mathrm{g}$ sample and 133.40 to $320.30 \mu \mathrm{mol}$ of trolox/g sample, respectively. However, Paz et al. (2015) showed levels of $1.81 \mathrm{mg} \mathrm{GAE} / \mathrm{g}$ sample and $1.57 \mathrm{mg}$ of Trolox/g açaí from Brazil’s Amazon Forest, for phenolic compounds and antioxidant activity, respectively.

Blueberry extract showed a variation from 6.01 to $17.91 \mathrm{mg}$ GAE/g sample and from 8.89 to $49.53 \mu \mathrm{mol}$ of trolox/g sample for TPC and AA, respectively. The highest phenolic compounds content found in blueberry was in treatment A8. In this condition (A8 assay) the compounds extracted from blueberry had the highest AA and significantly differed from the other treatments (Table 1). This shows ethanol was the most suitable solvent for the extraction of phenolic compounds in blueberry. Pertuzatti et al. (2014), studied ten blueberry Brazillian cultivars and found small amounts of TPC, those values ranged from 1.62 to $3.45 \mathrm{mg}$ GAE/g of açaí. For other hand, Castrejón et al. (2008) studying blueberry varieties in different ripening stages from Berlin, Germany, found high TPC levels from 17.3 to $52.6 \mathrm{mg} \mathrm{GAE} / \mathrm{g}$ sample.

The TPC and AA for goji berry extracts ranged from 11.77 to $21.62 \mathrm{mg} \mathrm{GAE} / \mathrm{g}$ sample and from 8.89 to $19.40 \mu \mathrm{mol}$ of Trolox/g sample, respectively. The A7 treatment showed the highest TPC and significantly differed from other treatments. The water is the most suitable solvent for phenolic compounds extraction from goji berry, however, the largest AA values for this fruit extract was found in assay A8, with $19.40 \mu \mathrm{mol}$ of Trolox/g sample (Table 1). Our results showed lower TPC values than found by Donno et al. (2015) in the goji berry from Alzate di Momo in the Northern Italy, who found phenolic compounds levels ranging from 255.87 to $281.81 \mathrm{mg} \mathrm{GAE} / \mathrm{g}$ sample.
These differences are usually caused by the great diversity of chemical compounds that can be extracted depending on the methodology used.

The wide range of studies related to conditions and extraction methods of phenolic compounds and antioxidant activity makes it difficult to perform an effective comparison. In addition, the large differences in TPC and AA values observed in these studies can be also attributed to different climactic conditions during cultivation of the fruits due to the different regions where each one fruit was planted. The harvest season is also an important factor for comparison.

The analysis of variance (ANOVA) of the dependent variable; TPC and AA from açaí, blueberry and goji berry subjected to extraction conditions presented by the factorial design is shown in Table 2. The factors time, temperature and solvent nature in the extraction of phenolic compounds and AA were significant $(\mathrm{p}<0.05)$ for all fruits. The analysis of variance, $\mathrm{F}_{\text {calc }}$ for all response variables (TPC and AA) was always greater than $\mathrm{F}_{\text {tabulated }}$ (4.45), and in some cases, this amount was about 80 times greater than $\mathrm{F}_{\text {tabulated }}$ (Table 2). The lower ratio found in $\mathrm{F}_{\text {calc }}$ by $F_{\text {tabulated }}$ in the analysis of variance was 5.85 . These results showed that the empirical data were adequately adjusted to the proposed models.

The global response (GR) showed that the kind of solvent was the mostly independent variable to extract the phenolic compounds from açaí, blueberry and goji berry. The effect estimated for solvent type was 1.34 , while for extraction time and extraction temperature were 0.52 and 0.51 , respectively. All effect estimated were significant $\left(p_{\text {value }}<0.0000\right)$. Thus the best conditions for phenolic compounds extraction with antioxidant activity from fruits was found when the ethanol was used as extractor solvent in the extraction temperature at $60^{\circ} \mathrm{C}$ during 60 minutes (Table 3).

The entire data set was adjusted by multiple linear regression and six linear mathematical models were generated established by factorial design and response surface methodology (RSM) (Table 4). The TPC and AA answers were significant at the $5 \%$ level for each fruit (Table 4). For each model, we observed a high coefficient correlation varying from 0.81 to 0.98 , thus 81 to $98 \%$ of data can be explained by the proposed models (Table 4).

Each multiple linear regression model generates a response surface, where the dependent variables (TPC and AA) are shown on the $\mathrm{z}$ axis as a function of the independent variables; solvent nature, extraction time and extraction temperature (Figs. 1 to 3). High values TPC from açaí were obtained with pure water as solvent at $60{ }^{\circ} \mathrm{C}$ during 
de Moura, et al.

Table 2: Analysis of variance of responses of the TPC and AA in fruits subjected to treatments according to a Fractional Design

\begin{tabular}{|c|c|c|c|c|c|c|c|c|c|c|}
\hline \multirow[t]{2}{*}{ Source of variation } & \multicolumn{5}{|c|}{$\begin{array}{l}\text { Açaí/Dependent variable: Phenolic compounds } \\
\text { total }\end{array}$} & \multicolumn{5}{|c|}{$\begin{array}{l}\text { Açaí/Dependent variable: Antioxidant activity by DPPH } \\
\text { method }\end{array}$} \\
\hline & SS & DF & MS & $F_{\text {calc }}$ & $p$ value & SS & DF & MS & $F_{\text {calc }}$ & $p$ value \\
\hline Solvent (X1) & 59.7242 & 1 & 59.72415 & 39.54818 & 0.000008 & 2442.325 & 1 & 2442.325 & 350.8172 & 0.000000 \\
\hline Time (X2) & 23.6017 & 1 & 23.60167 & 15.62857 & 0.001026 & 59.633 & 1 & 59.633 & 8.5657 & 0.009414 \\
\hline Temperature (X3) & 12.4993 & 1 & 12.49927 & 8.27677 & 0.010461 & 2.026 & 1 & 2.026 & 0.2910 & 0.596571 \\
\hline $\mathrm{X} 1 ; \mathrm{X} 2$ & 0.0661 & 1 & 0.06615 & 0.04380 & 0.836708 & 187.416 & 1 & 187.416 & 26.9206 & 0.000074 \\
\hline $\mathrm{X} 1 ; \mathrm{X} 3$ & 2.8704 & 1 & 2.87042 & 1.90073 & 0.185869 & 48.932 & 1 & 48.932 & 7.0286 & 0.016800 \\
\hline $\mathrm{X} 2 ; \mathrm{X} 3$ & 9.6774 & 1 & 9.67740 & 6.40819 & 0.021515 & 0.010 & 1 & 0.010 & 0.0014 & 0.970142 \\
\hline Residue & 25.6728 & 17 & 1.51016 & & & 118.351 & 17 & 6.962 & & \\
\hline Total & 134.1118 & 23 & & & & 2858.692 & 23 & & & \\
\hline \multirow[t]{2}{*}{ Source of variation } & \multicolumn{5}{|c|}{$\begin{array}{l}\text { Blueberry/Dependent variable: Phenolic } \\
\text { compounds total }\end{array}$} & \multicolumn{5}{|c|}{$\begin{array}{l}\text { Blue berry/Dependent variable: Antioxidant activity by } \\
\text { DPPH method }\end{array}$} \\
\hline & SS & DF & MS & $F_{\text {calc }}$ & $p$ value & sS & DF & MS & $F_{\text {calc }}$ & $p$ value \\
\hline Solvent (X1) & 412.4275 & 1 & 412.4275 & 1108.144 & 0.000000 & 4132.223 & 1 & 4132.223 & 730.878 & 0.000 \\
\hline Time (X2) & 8.8452 & 1 & 8.8452 & 23.766 & 0.000142 & 163.104 & 1 & 163.104 & 28.849 & 0.000 \\
\hline Temperature (X3) & 19.2425 & 1 & 19.2425 & 51.702 & 0.000002 & 210.326 & 1 & 210.326 & 37.201 & 0.000 \\
\hline $\mathrm{X} 1 ; \mathrm{X} 2$ & 0.0176 & 1 & 0.0176 & 0.047 & 0.830418 & 113.144 & 1 & 113.144 & 20.012 & 0.000 \\
\hline $\mathrm{X} 1 ; \mathrm{X} 3$ & 0.0513 & 1 & 0.0513 & 0.138 & 0.714928 & 75.275 & 1 & 75.275 & 13.314 & 0.002 \\
\hline $\mathrm{X} 2 ; \mathrm{X} 3$ & 0.8932 & 1 & 0.8932 & 2.400 & 0.139755 & 102.308 & 1 & 102.308 & 18.096 & 0.001 \\
\hline Residue & 6.3270 & 17 & 0.3722 & & & 96.114 & 17 & 5.654 & & \\
\hline Total & 447.8044 & 23 & & & & 4892.494 & 23 & & & \\
\hline \multirow[t]{2}{*}{ Source of variation } & \multicolumn{5}{|c|}{$\begin{array}{l}\text { Goji berry/Dependent variable: Phenolic } \\
\text { compounds total }\end{array}$} & \multicolumn{5}{|c|}{$\begin{array}{l}\text { Goji berry/Dependent variable: Antioxidant activity by } \\
\text { DPPH method }\end{array}$} \\
\hline & SS & DF & MS & $F_{\text {calc }}$ & $p$ value & SS & DF & MS & $F_{\text {calc }}$ & $p$ value \\
\hline Solvent (X1) & 51.8322 & 1 & 51.83220 & 32.09225 & 0.000028 & 245.504 & 1.000 & 245.504 & 276.756 & 0.000 \\
\hline Time (X2) & 51.8910 & 1 & 51.89100 & 32.12866 & 0.000028 & 16.537 & 1.000 & 16.537 & 18.642 & 0.000 \\
\hline Temperature (X3) & 41.8968 & 1 & 41.89684 & 25.94070 & 0.000090 & 32.313 & 1.000 & 32.313 & 36.426 & 0.000 \\
\hline $\mathrm{X} 1 ; \mathrm{X} 2$ & 0.2262 & 1 & 0.22620 & 0.14006 & 0.712853 & 0.910 & 1.000 & 0.910 & 1.026 & 0.325 \\
\hline $\mathrm{X} 1 ; \mathrm{X} 3$ & 5.4626 & 1 & 5.46260 & 3.38221 & 0.083437 & 2.331 & 1.000 & 2.331 & 2.628 & 0.123 \\
\hline $\mathrm{X} 2 ; \mathrm{X} 3$ & 5.4435 & 1 & 5.44354 & 3.37040 & 0.083932 & 5.191 & 1.000 & 5.191 & 5.852 & 0.027 \\
\hline Residue & 27.4567 & 17 & 1.61510 & & & 15.080 & 17.000 & 0.887 & & \\
\hline Total & 184.2091 & 23 & & & & 317.867 & 23.000 & & & \\
\hline
\end{tabular}

* Values in italic refer to significant differences, $F_{0.05 ; 2 ; 17}=3.59, F_{0.05 ; 3 ; 17}=3.20, F_{0.05 ; 5 ; 17}=2.81$; SS: Sum of squares; DF: Degree of freedom; MS: Mean of squares

60 min (Fig. 1a). On the other hand, ethanol $(800 \mathrm{~g} / \mathrm{L})$ at a temperature of $60{ }^{\circ} \mathrm{C}$ and for $60 \mathrm{~min}$ was the best extraction condition for phenolic compounds with high antioxidant activity (Fig. 1b).

The best solvent to extract goji berry TPC was pure water (Fig. 2a), however, this solvent was not the best option for extracting phenolic compounds with antioxidant activity, in this case ethanol $800 \mathrm{~g} / \mathrm{L}$ obtained better results (Fig. 2b). The variables time $(60 \mathrm{~min})$ and temperature $\left(60^{\circ} \mathrm{C}\right) \mathrm{had}$ a positive effect on TPC and AA (Fig. $2 \mathrm{ab}$ ).

The best extraction conditions of blueberry phenolic compounds were ethanol $800 \mathrm{~g} / \mathrm{L}$ at $60^{\circ} \mathrm{C}$ during $60 \mathrm{~min}$, showing the most extreme time and temperature conditions led to an increased TPC extraction (Fig. 3a) with greater AA (Fig. 3b). Generally, this same result was observed with the other fruits. Thus, the optimum extraction condition for phenolic compounds with high antioxidant activity was obtained with the ethanol $(800 \mathrm{~g} / \mathrm{L})$ at $60^{\circ} \mathrm{C}$ during 60 minute of extraction.
Oldoni et al. (2015), evaluated the extraction conditions of phenolic compounds from propolis with different ethanol concentrations, temperature and time. The authors reported that the best condition was found with ethanol $(800 \mathrm{~g} / \mathrm{L})$ at $70^{\circ} \mathrm{C}$ during $45 \mathrm{~min}$ of extraction. Melo et al. (2015) evaluated the best ratio of ethanol and extraction time in winery byproducts, and concluded that moderate ethanol concentrations $(430 \mathrm{~g} / \mathrm{L}$ and $570 \mathrm{~g} / \mathrm{L})$, combined with high temperatures $\left(96^{\circ} \mathrm{C}\right)$ were the best conditions for antioxidants extraction.

The principal component analysis (PCA) was performed on the data set of anthocyanin and antioxidant activity levels. Two major components were identified, with $99.50 \%$ of explained variance, PC1 for $88.16 \%$ variation, and PC2 for $11.33 \%$ (Fig. 4ab). There was the formation of three groups represented by the analyzed fruits (açaí, blueberry and goji berry) and distributed in the quadrants of the PCA scores chart (Fig. 4a).

The first group is represented by açaí (second quadrant Fig. 4b), which has a high antioxidant activity by ABTS, 
$\beta$-carotene and FRAP. Blueberry extract (third quadrant Fig. 4b) showed high anthocyanin content. The other group, also as sole representative was the goji berry group (quadrants 1 and 4), which showed high $\mathrm{EC}_{50}$ values. The two most important dependent variables in groups formation and occurrence were the antioxidant activity by FRAP and $\mathrm{EC}_{50}$, taking into account their commonalities. The least important variable in group classification was anthocyanin content. Groupings of açaí, blueberry and goji berry fruit extracts because of their antioxidant activities and anthocyanin content could be analyzed by PCA. In addition, ANOVA test and PCA confirmed the anthocyanin and antioxidant activity results significantly contributing to improve the knowledge of this three fruits analyzed.

\section{Fruit extracts chemical characterization and antioxidant activity in the best extraction condition}

The extracts of the three fruits in the best extraction condition (ethanol at $60{ }^{\circ} \mathrm{C}$ and $60 \mathrm{~min}$ of extraction), A8 assay, were analyzed for total anthocyanin, AA by four different methods ( $\mathrm{EC}_{50}$, FRAP, ABTS and $\beta$-carotene) and phenolic compounds profile by HPLC/DAD.

Total anthocyanin content ranged from 4.17 to $874.17 \mathrm{mg} / 100 \mathrm{~g}$ of fruit (Table 5). The highest and lowest anthocyanin concentrations were found in blueberry and goji berry, respectively, with a statistically significant difference (Table 5). In this study the total anthocyanin content of the blueberry $(874.17 \mathrm{mg} / 100 \mathrm{~g})$ was found to be higher than fiveten blueberry Brazillian cultivars

Table 3: Analysis of variance of global response in fruits subjected to treatments according to a Fractional Design

\begin{tabular}{lccccc}
\hline Source of & \multicolumn{5}{c}{ Dependent variable: } \\
\cline { 2 - 6 } variation & SS & DF & MS & $F_{\text {calc }}$ & $p$ value \\
\hline Solvent $(\mathrm{X} 1)$ & 10.7325 & 1 & 10.7325 & 659.9356 & 0.0000 \\
Time (X2) & 1.5724 & 1 & 1.5724 & 96.6864 & 0.0000 \\
Temperature & 1.5647 & 1 & 1.5647 & 96.2116 & 0.0000 \\
$(\mathrm{X} 3)$ & & & & & \\
X1;X2 & 0.2426 & 1 & 0.2426 & 14.9163 & 0.0012 \\
X1;X3 & 0.1136 & 1 & 0.1136 & 6.9859 & 0.0170 \\
X2;X3 & 0.3454 & 1 & 0.3454 & 21.2383 & 0.0002 \\
Residue & 0.2765 & 17 & 0.0163 & & \\
Total & 14.8476 & 23 & & & \\
\hline
\end{tabular}

* Values in italic refer to significant differences, $\mathrm{F}_{0.05 ; 5 ; 17}=2.81$ studied (40.62 to $378.31 \mathrm{mg} / 100 \mathrm{~g}$ ), which were reported by Rodrigues et al. (2011). Our results for AA from açaí was higher than the findings of Yuyama et al. (2011) and Borges et al. (2016), who reported anthocyanin content in açaí from Brazil ranging between 128.40 to $868.91 \mathrm{mg} / 100 \mathrm{~g}$ and 40.6 to $74.2 \mathrm{mg} / 100 \mathrm{~g}$, respectively. The differences between the values found in this study can be due to methodological differences employed in the extraction of this compound class (Table 5).

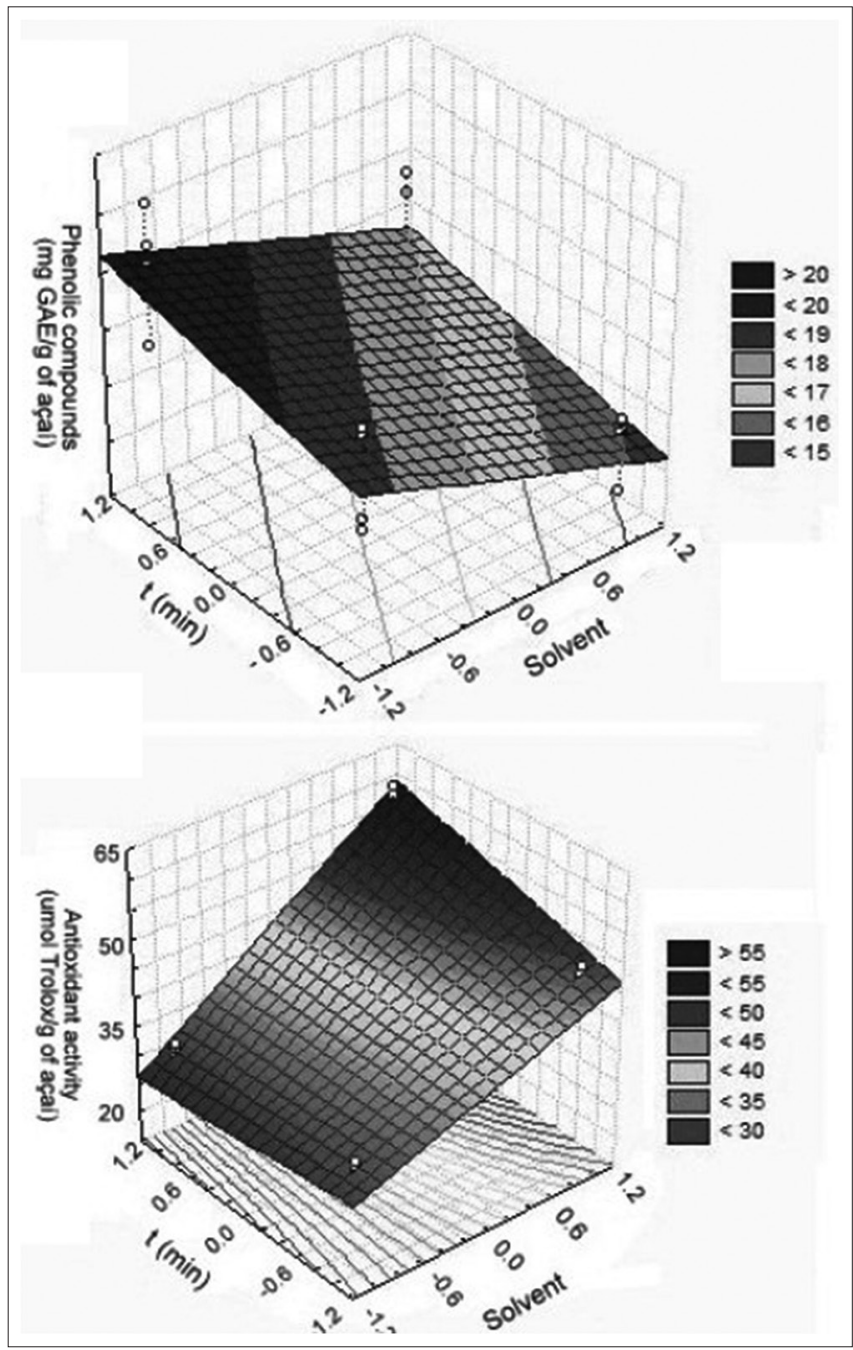

Fig 1. Reponse surface of the TPC (1a) in $\mathrm{mg} \mathrm{GAE} / \mathrm{g}$ of acai and AA (1b) in $\mu \mathrm{mol}$ Trolox/g of acai as a function of time and solvent nature

Table 4: Models generated for analysis of variance of the TPC and AA in açaí, blueberry and goji berry subjected to treatments, according to a Fractional Design (FD)

\begin{tabular}{|c|c|c|}
\hline Equation number & Model generated & Correlation coefficient $\mathbf{R}^{2}$ \\
\hline 2 & TPC açaí $=17.66-1.58 \chi_{1}+0.99 \chi_{2}+0.72 \chi \_3+0.64 \chi 1 \chi_{2}$ & 0.81 \\
\hline 3 & $A A$ açaí $=40.72+10.09 \chi_{1}+1.57 \chi_{2}+2.79 \chi_{1} \times \_2+1.43 \chi_{2} \chi_{3}$ & 0.94 \\
\hline 5 & AA blueberry $=23.34+13.12 \chi_{1}+2.61 \chi_{2}+2.96 \chi_{3}+2.17 \chi_{1} \chi_{2}+1.77 \chi_{1} \chi_{3}+2.06 \chi_{2} \chi_{3}$ & 0.97 \\
\hline 6 & TPC goji berry $=15.84-1.47 \chi_{1}+1.47 \chi_{-2}+1.32 \chi_{3}$ & 0.85 \\
\hline 7 & $A A$ goji berry $=13.172+3.198 \chi_{1}+0.830 \chi_{2}+1.160 \chi_{3}+0.312 \chi_{1} \chi_{3}$ & 0.93 \\
\hline 8 & $G R=3.84+0.67 \chi_{1}+0.25 \chi_{2}+0.25 \chi_{3}+0.10 \chi_{1} \chi_{2}+0.07 \chi_{1} \chi_{3}+0.12 \chi_{2} \chi_{3}$ & 0.98 \\
\hline
\end{tabular}

Response: TPC: Total phenolic compounds; AA: Antioxidant activity; GR: Global response - X1: solvent; X2: time; X3: temperature. 
The antioxidant activity in each fruit extract differed significantly $(\mathrm{p}<0.05)$ between analyzed methods (Table 5$)$. Açaí extract showed superiority in antioxidant activity by the FRAP, ABTS and $\beta$-carotene method, while blueberry was superior through the DPPH test expressed as $\mathrm{EC}_{50}$. Goji berry had the lowest antioxidant activity in all tests compared to açaí and to blueberry (Table 5).

Antioxidant activity of sodium erythorbate was used as positive control and for comparison with the samples

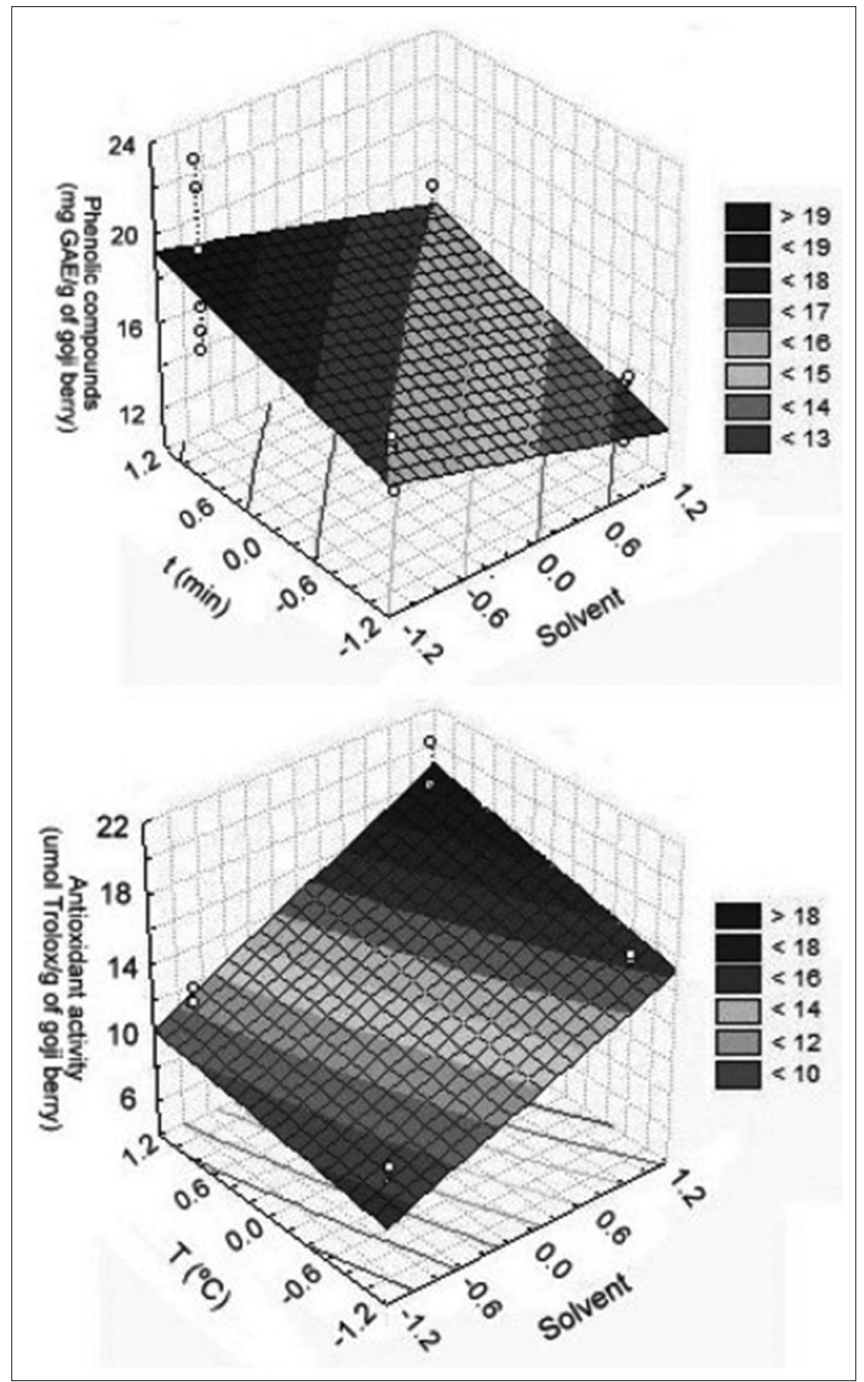

Fig 2. Reponse surface of the TPC (2a) in mg GAE/g of goji berry as a function of time and solvent nature and $A A(2 b)$ in $\mu \mathrm{mol}$ Trolox/g of goji berry as a function of temperature and solvent nature with values of $0.05 \pm 0.01 \mathrm{mg} / \mathrm{mL}, 2871.97 \pm 26.97 \mu \mathrm{mol}$ $\mathrm{Fe}^{2+} / \mathrm{g}$ sample, $4777.93 \pm 206.00 \mu \mathrm{mol}$ Trolox/g sample and $77.27 \% \pm 0.07$, through the $\mathrm{EC}_{50}$, FRAP, ABTS and $\beta$-carotene method, respectively. These values were higher than those of the analyzed samples (Table 5), once sodium erythorbate - a chemical preservative much used in fruit products - is a pure substance when compared with fruits extract, which contain many other extracted compounds that can interfere with the chemical analysis.

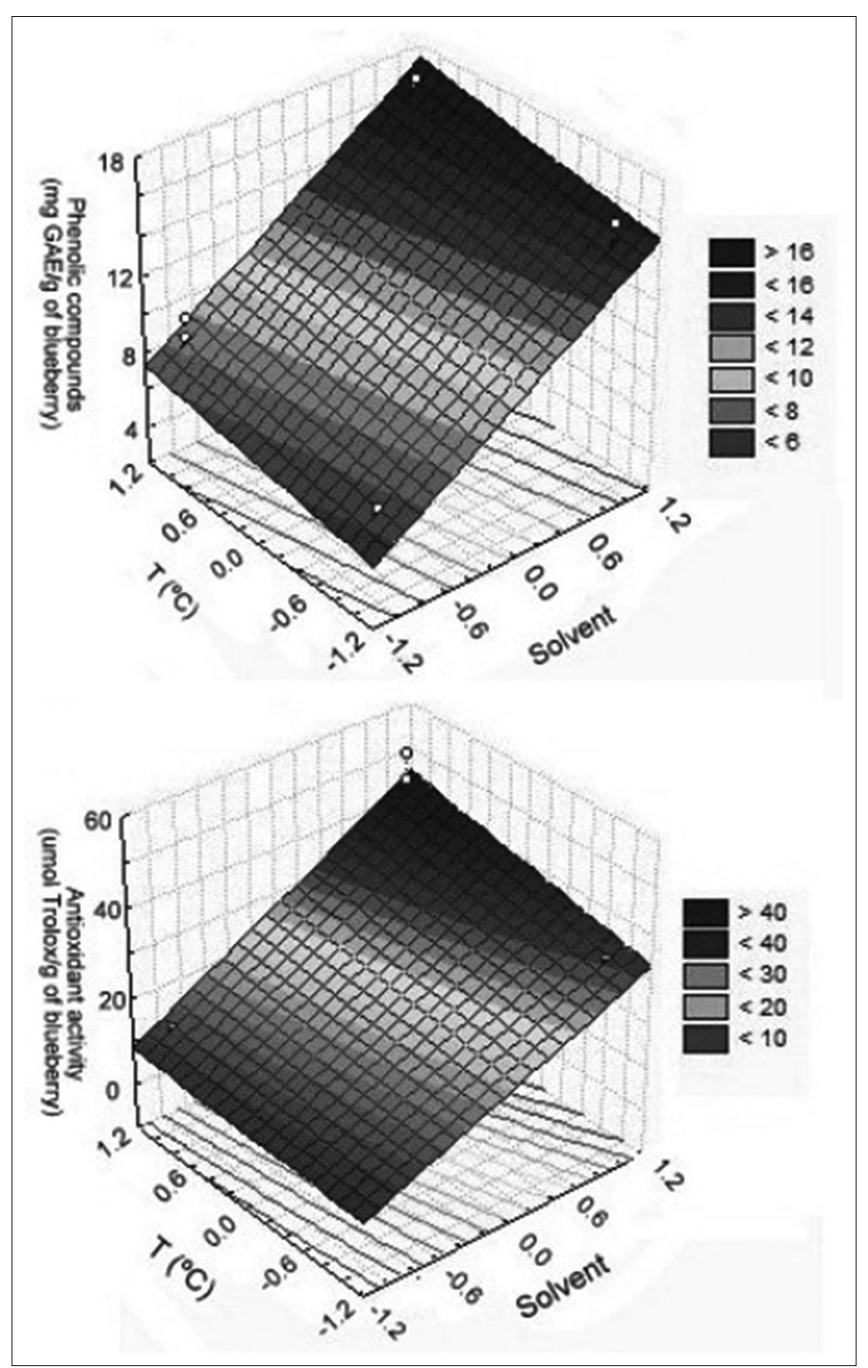

Fig 3. Reponse surface of the TPC (3a) in mg GAE/g of blueberry and (3b) in $\mu \mathrm{mol}$ Trolox/g of blueberry as a function of temperature and solvent nature

Table 5: Total anthocyanin and antioxidant activity by different methods for açaí, blueberry and goji berry fruits in the best extraction condition

\begin{tabular}{|c|c|c|c|c|c|}
\hline Fruits & $\begin{array}{l}\text { Total anthocyanin } \\
(\mathrm{mg} / 100 \mathrm{~g})\end{array}$ & $\begin{array}{c}E C_{50} \\
(\mathrm{mg} / \mathrm{mL})\end{array}$ & $\begin{array}{c}\text { FRAP } \\
\left(\mu \mathrm{mol} \mathrm{de} \mathrm{Fe}^{2+} / \mathrm{g}\right)\end{array}$ & $\begin{array}{c}\text { ABTS } \\
(\mu \mathrm{mol} \text { Trolox } / \mathrm{g})\end{array}$ & $\begin{array}{c}\beta \text {-caroteno } \\
(\%)\end{array}$ \\
\hline Açaí & $410.24 \pm 1.18^{b}$ & $0.62 \pm 0.01^{b}$ & $106.35 \pm 0.61^{a}$ & $15.28 \pm 0.16^{a}$ & $74.66 \pm 0.63^{a *}$ \\
\hline Blueberry & $874.17 \pm 3.61^{a}$ & $0.50 \pm 0.03^{a}$ & $99.38 \pm 0.76^{b}$ & $13.11 \pm 0.04^{b}$ & $66.28 \pm 0.29^{\mathrm{b} *}$ \\
\hline Goji berry & $4.17 \pm 0.83^{c}$ & $2.48 \pm 0.02^{c}$ & $47.54 \pm 0.55^{c}$ & $10.67 \pm 0.03^{c}$ & $47.14 \pm 0.46^{\mathrm{c} *}$ \\
\hline Pooled SD & 351.28 & 0.90 & 26.32 & 1.98 & 11.26 \\
\hline
\end{tabular}

$\mathrm{EC}_{50}$ : Equivalent concentration; *concentration: $0.01 \mathrm{~g} / \mathrm{mL}:{ }^{* *} 0.03 \mathrm{~g} / \mathrm{mL}$ 
Table 6: Phenolic profile determined by HPLC in açaí, blueberry and goji berry extracts

\begin{tabular}{|c|c|c|c|c|c|c|}
\hline Compounds & TR (min) & RE (Correlation coefficient) & $\begin{array}{c}\text { Açaí } \\
\text { (mg/g) }\end{array}$ & Blueberry (mg/g) & Goji berry (mg/g) & Pooled SD \\
\hline Catequin & 11.64 & $y=0.064 x+0.129\left(R^{2}=0.988\right)$ & $0.023 \pm 0.001$ & $0.056 \pm 0.001$ & $0.050 \pm 0.002$ & 0.014 \\
\hline Cafeic acid & 15.68 & $y=0.071 x+0.207\left(R^{2}=0.988\right)$ & n.d. & $0.017 \pm 0.001$ & $0.151 \pm 0.002$ & 0.067 \\
\hline Epicatequin & 17.77 & $y=0.065 x+0.137\left(R^{2}=0.988\right)$ & $0.030 \pm 0,001$ & $0.008 \pm 0.001$ & n.d. & 0.011 \\
\hline Cumaric acid & 22.07 & $y=0.349 x+1.095\left(R^{2}=0.988\right)$ & n.d. & n.d. & $0.123 \pm 0.005$ & 0.003 \\
\hline Ferulic acid & 23.71 & $y=0.061 x+0.196\left(R^{2}=0.989\right)$ & n.d. & $0.119 \pm 0.002$ & $0.069 \pm 0.001$ & 0.025 \\
\hline Rutin & 24.89 & $y=0.145 x+0.428\left(R^{2}=0.988\right)$ & $0.001 \pm 0.000$ & $0.091 \pm 0.000$ & $0.326 \pm 0.001$ & 0.137 \\
\hline Myricetin & 27.95 & $y=0.066 x-0.158\left(R^{2}=0.989\right)$ & $0.054 \pm 0.001$ & n.d. & n.d. & 0.001 \\
\hline
\end{tabular}

TR: Retention time; RE: Regression equation; Detection and quantification limits were defined as the concentration of $0.12 \mu \mathrm{g} / \mathrm{mL}$ and $0.35 \mu \mathrm{g} / \mathrm{mL}$, respectively

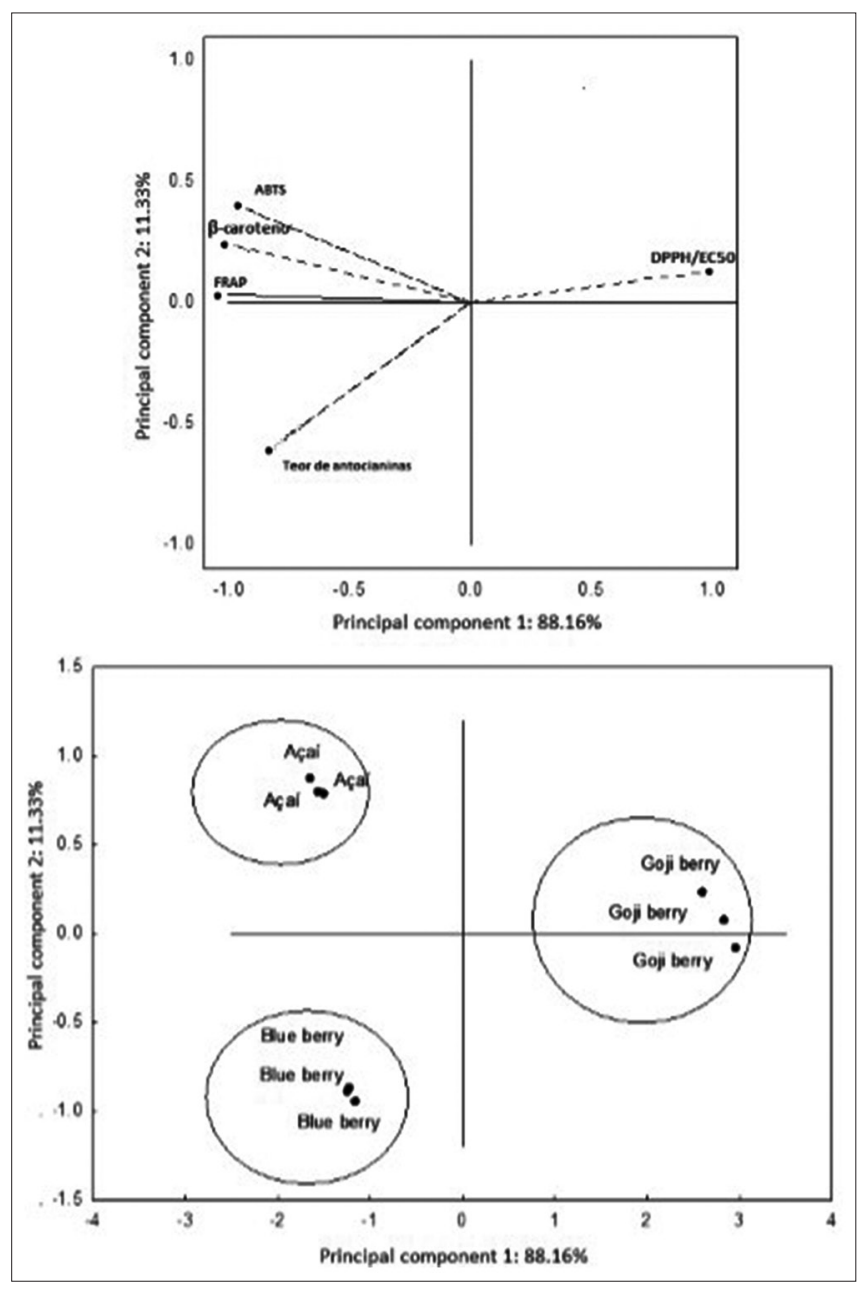

Fig 4. PCA plot Antioxidant activity and total anthocyanin on the acai, blueberry and goji berry a) scores; b) loding plot for the antioxidant actitivty and total anthocyanin on prinicipal 1 and 2

The highest antioxidant activity performed through DPPH method and expressed as $\mathrm{EC}_{50}$ (concentration of extract necessary to decrease the initial concentration of DPPH by $50 \%)$ was found in blueberry $(0.50 \mathrm{mg} / \mathrm{mL})$, and calculated through the line equation $\mathrm{y}=79.141 \mathrm{x}+10.647\left(\mathrm{R}^{2}=0.990\right)$. Goji berry showed the lowest antioxidant activity with $\mathrm{EC}_{50}$ of $2.48 \mathrm{mg} / \mathrm{mL}\left(\mathrm{y}=20.303 \mathrm{x}-0.7711, \mathrm{R}^{2}=0.996\right)$ (Table 5).

ABTS radical scavenging performed using the line equation $y=-11.244 x+0.689\left(R^{2}=0.997\right)$ ranged from 10.675 $\mu \mathrm{mol}$ Trolox/g (goji berry) to $15.285 \mu \mathrm{mol}$ Trolox/g (açai) (Table 5). These results were similar to those reported by Santos et al. (2008) who obtained values between 10.21 and $52.47 \mu \mathrm{mol}$ of Trolox/g sample in açaí Brazillian commercial pulps, still Pertuzatti et al. (2014) found values from 40.30 to $260.80 \mu \mathrm{mol}$ Trolox/g in blueberry Brazilian varieties.

The reducing activity power of $\mathrm{Fe}^{3+}$ to $\mathrm{Fe}^{2+}$ (FRAP) of fruit extracts was calculated using the line equation $y=32.991 \mathrm{x}-0.050$ with $\mathrm{R}^{2}$ of 0.999 and ranged from 47.54 to $106.35 \mu \mathrm{mol} \mathrm{Fe}{ }^{2+} / \mathrm{g}$ sample (Table 5). Açaí and goji berry showed the highest and lowest values, respectively (Table 5) and differed statistically $(\mathrm{p}<0.05)$. The antioxidant activity by coupled $\beta$-carotene/ linoleic acid method at a concentration of $0.01 \mathrm{~g} / \mathrm{mL}$ for blueberry and açaí samples and at $0.025 \mathrm{~g} / \mathrm{ml}$ for goji berry, ranged from 74.66 to $47.14 \%$. The highest values was found in açaí extract and smaller values in goji berry extract (Table 5).

Donno et al. (2015) found $20.89 \mu \mathrm{mol} \mathrm{Fe} \mathrm{F}^{2+} / \mathrm{g}$ in the goji berry from Italy and was lower than those found in this study (Table 5). Pertuzatti et al. (2014) achieved antioxidant activity of $60.9 \%$ by the $\beta$-carotene/linoleic acid method in the blueberry extracts $(0.46 \mathrm{~g} / \mathrm{mL}$ concentration) with similar results of this study (Table 5).

The quantification of the phenolic compounds by highperformance liquid chromatography in the açaí, blueberry and goji berry extracts was performed in different wavelengths from 277 to $371 \mathrm{~nm}$. Retention times, wavelengths and regression equation data of compounds are given in Table 6. It was possible to visualize the presence of catechin and rutin flavonoids in the three studied fruit extracts (Table 6). Catechin, epicatechin, rutin and myricetin were found in açaí, among them myricetin $(0.054 \mathrm{mg} / \mathrm{g})$ and rutin $(0.001 \mathrm{mg} / \mathrm{g})$ were present in higher and lower concentration, respectively. No phenolic acids were found in the açaí extracts (Table 6).

Catechin, epicatechin, caffeic acid, ferulic acid and rutin were found in blueberry extract. In this extract, epicatechin $(0.008 \mathrm{mg} / \mathrm{g})$ and ferulic acid $(0.119 \mathrm{mg} / \mathrm{L})$ were the phenolic compounds found in lower and higher concentrations, respectively (Table 6). 
Three phenolic acids (caffeic acid, coumaric acid, ferulic acid) and two flavonoids (catechin, rutin) were found in goji berry extract in concentrations ranging from $0.050 \mathrm{mg} / \mathrm{L}$ (catechin) to $0.326 \mathrm{mg} / \mathrm{L}$ (rutin) (Table 6).

Studies for identification and quantification of phenolic compounds from fruits are common (Castrejón et al., 2008; Yuyama et al., 2011; Borges et al., 2016), however, the method used in extraction, equipment, identification and separation conditions are different. Furthermore, the wide species diversity and crops types make it relatively difficult to compare these studies (Rodrigues et al., 2011; Melo et al., 2015). Donno et al. (2015) found caffeic acid, coumaric acid, ferulic acid and epicatechin in goji berry from Italy, while Wang et al. (2010) in their studies found another composition in the same fruit (rutin, quercetin and caffeic acid). The phenolic compound contents found by these authors were higher than those found in this study (Table 6). Gordon et al. (2012) in their studies with açaí had previously identified, compounds like gallic acid, caffeic acid, and vanillic acid.

\section{CONCLUSION}

Experimental design and RSM could be used to optimize extraction of phenolic compounds from açaí, blueberry and gojy berry for maximizing the antioxidant capacity. Further, the use of global response was very useful for simplifying and improving the phenolic compounds extraction performance with high antioxidant activity. In the best extraction condition it was possible to extract phenolic compounds such as phenolic acids and flavonoids with high antioxidant activity. The açaí, blueberry and gojy berry extracts obtained in this study can be a potential source of the phenolic compounds for food technology application, as natural antioxidant alternatives.

\section{ACKNOWLEDGMENTS}

The authors thank the Brazilian National Research Council for financial support, Coordination for the Improvement of Higher Level Personnel (CAPES), Araucaria Research Foundation for the scholarships and Analysis Center at UTFPR-Pato Branco/PR.

\section{Author's contributions}

C. M.: Designed the study and colected of the samples, did the analysis; A. S. R. and L. D. S.: Participate on carrying out experiments as antioxidant activity; V. A. L.: Was involved in designing the study and statistical analysis; T. L. C. O.: Was involved in HPLC analysis; C. P.: Was involved in literature collection; S. T. C.: Was involved in manuscript preparation and supervised the research project.

\section{REFERENCES}

Ahn, M., S. Kumazawa, T. Hamasaka, K. Bang and T. Nakayama. 2004. Antioxidant activity and constituents of propolis collected in various areas of Korea. J. Agric. Food Chem. 52: 7286-7292.

Amagase, H. and N. R. Farnsworth. 2011. A review of botanical characteristics, phytochemistry, clinical relevance in efficacy and safety of Lycium barbarum fruit (Goji). Food Res. Int. 44: 1702-1717.

Belda-Galbis, C. M., A. Jiménez-Carretón, M. C. Pina-Pérez, A. Martínez and D. Rodrigo. 2015. Antimicrobial activity of açai against Listeria innocua. Food Control. 53: 212-216.

Borges, P. R. S., E. G. Tavares, I. C. Guimarães, R. P. Rocha, A. B. S. Araujo, E. E. Nunes and E. V. B. V. Boas. 2016. Obtaining a protocol for extraction of phenolics from açaí fruit pulp through plackett-burman design and response surface methodology. Food Chem. 210: 189-199.

Brand-Williams, W., M. E. Cuvelier and C. Berset. 1995. Use of a free radical method to evaluate antioxidant activity. LWT Food Sci. Technol. 28: 25-30.

Carnés, J., C. H. de Larramendi, A. Ferrer, A. J. Huertas, M. A. López-Matas, J. A. Pagán, L. Navarro, J. L. García-Abujeta, S. Vicario and M. Peña. 2013. Recently introduced foods as new allergenic sources: Sensitisation to Goji berries (Lycium barbarum). Food Chem. 137: 130-135.

Castrejón, A. D. R., I. Eichholz, S. Rohn, L. W. Kroh and S. HuyskensKeil. 2008. Phenolic profile and antioxidant activity of highbush blueberry (Vaccinium corymbosum L.) during fruit maturation and ripening. Food Chem. 109: 564-572.

Choi, Y. J., Y. J. Choi, N. Kim, R. H. Nam, S. Lee, H. S. Lee, H. N. Lee, Y. J Surth and D. H. Lee. 2017. Açai berries inhibit colon tumorigenesis in azoxymethane/dextran sulfate sodium-treated mice. Gut Liver. 11: 243-252.

Dong, J. Z., W. S. Gao, D. Y. Lu and Y. Wang. 2009. Simultaneous extraction and analysis of four polyphenols from leaves of Lycium barbarum L. J. Food Biochem. 35: 914-931.

Donno, D., G. L. Beccaro, M. G. Mellano, A. K. Cerutti and G. Bounous. 2015. Goji berry fruit (Lycium spp.): Antioxidant compound fingerprint and bioactivity evaluation. J. Funct. Foods. 18: 1070-1085.

Favacho, H. A. S., B. R. Oliveira, K. C. Santos, B. J. L. Medeiros, P. J. C. Sousa, F. F. Perazzo and J. C. T. Carvalho. 2011. Antiinflammatory and antinociceptive activities of Euterpe oleracea Mart., Arecaceae, oil. Rev. Bras. Farmacogn. 21: 105-114.

Giusti, M. M. and R. E. Wrolsted. 2001. Anthocyanins: Characterization and measurement with UV-visible spectroscopy. In: Wrolstad, R. E., S. J. Schwartz (Eds.,), Current Protocols in Food Analytical Chemistry, Wiley, New York.

Gordon, A., A. P. G. Cruz, L. M. C. Cabral, S. C. de Freitas, C. M. A. D. Taxi, C. M. Donangelo, R. de A. Mattietto, M. Friedrich, V. M. da Matta and F. Marx. 2012. Chemical characterization and evaluation of antioxidant properties of açaí fruits (Euterpe oleraceae Mart.) during ripening. Food Chem. 133: 256-263.

Hammer, Ø., D. A. T. Harper and P. D. Ryan. 2001. PAST: Paleontological statistics software package for education and data analysis. Palaeontol. Electron. 4: 1-9.

Kang, J., K. M. Thakali, C. Xie, M. Kondo, Y. Tong, B. Ou, G. Jensen, M. B. Medina, A. G. Schauss and X. Wu. 2012. Bioactivities of açaí (Euterpe precatoria Mart.) fruit pulp, superior antioxidant and anti-inflammatory properties to Euterpe oleracea Mart. Food Chem. 133: 671-677.

Kang, J., C. Xie, Z. Li, S. Nagarajan, A. G. Schauss, T. Wu and X. Wu. 
2011. Flavonoids from açai (Euterpe oleracea Mart.) pulp and their antioxidant and anti-inflammatory activities. Food Chem. 128: $152-157$.

Koca, I. and B. Karadeniz. 2009. Antioxidant properties of blackberry and blueberry fruits grown in the black sea Region of Turkey. Sci Hortic. 121: 447-450.

Kulczyński, B. and A. Gramza-Michałowska. 2016. Goji berry (Lycium barbarum): Composition and health effects-A review. Pol. J. Food Nutr. Sci. 66: 67-75.

Leong, S. Y. and I. Oey. 2012. Effects of processing on anthocyanins, carotenoids and vitamin $C$ in summer fruits and vegetables. Food Chem. 133: 1577-1587.

Li, X. M., X. L. Li and A. G. Zhou. 2007. Evaluation of antioxidant activity of the polysaccharides extracted from Lycium barbarum fruits in vitro. Eur. Polym. J. 43: 488-497.

Lobo, V., A. Patil, A. Phatak and N. Chandra. 2010. Free radicals, antioxidants and functional foods: Impact on human health. Pharmacogn Rev. 4: 118-126.

Melo, P. S., A. P. Massarioli, C. Denny, L. F. dos Santos, M. Franchin, G. E. Pereira, T. M. F. S. Vieira, P. L. Rosalen and S. M. Alencar. 2015. Winery by-products: Extraction optimization, phenolic composition and cytotoxic evaluation to act as a new source of scavenging of reactive oxygen species. Food Chem. 181: $160-169$.

Moraes, J. O.,P. B. Pertuzatti, F. V. Corrêa and M. D. L. M. Salas-mellado. 2007. Study of rabbiteye blueberry (Vaccinium ashei Reade) in the process of food products. Food Sci. Technol. 27: 18-22.

Nardi, G. M., J. A. G, Farias, C. G. Freire, F. Megiolaro, K. Schneider, M. R. Perazzoli, S. R. do Nascimento, A. C. Gon, L. N. Mariano, G. Wagner, R. Niero and C. Locatelli. 2016. Anti-inflammatory activity of berry fruits in mice model of inflammation is based on oxidative stress modulation. Pharmacog. Res. 8: S42-S49.

Norberto, S., S. Silva, M. Meireles, A. Faria, M. Pintado and C. Calhau. 2013. Blueberry anthocyanins in health promotion: A metabolic overview. J. Funct. Foods. 5: 1518-1528.

Oldoni, T. L. C., S. C. Oliveira, S. Andolfatto, M. Karling, M. A. Calegari, R. Y. Sado, F. M. C. Maia, S. M. Alencar and V. A. Lima. 2015. Chemical characterization and optimization of the extraction process of bioactive compounds from propolis produced by selected bees. J. Braz. Chem. Soc. 26: 2054-2062.

Oliveira, D. D. S., P. P. Aquino, S. M. R. Ribeiro, R. P. D. C. Proença and H. M. Pinheiro-Sant'Ana. 2011. Vitamina C, carotenoides, fenólicos totais e atividade antioxidante de goiaba, manga e mamão procedentes da ceasa do estado de minas gerais. Acta Sci. Health Sci. 33: 89-98.

Paz, M., P. Gúllon, M. F. Barroso, A. P. Carvalho, V. F. Domingues, A. M. Gomes, H. Becker, E. Longhinotti and C. Delerue-Matos. 2015. Brazilian fruit pulps as functional foods and additives: Evaluation of bioactive compounds. Food Chem. 172: 462-468.

Perera, D., P. Soysa and S. Wijeratne. 2016. Polyphenols contribute to the antioxidant and antiproliferative activity of Phyllanthus debilis plant in-vitro. BMC Complement Altern Med. 16: 339.

Pertuzatti, P. B., M. T. Barcia, D. Rodrigues, P. N. da Cruz, I. HermosínGutiérrez, R. Smith and H. T. Godoy. 2014. Antioxidant activity of hydrophilic and lipophilic extracts of brazilian blueberries. Food Chem. 164: 81-88.

Potterat, O. 2010. Goji (Lycium barbarum and L. chinense): Phytochemistry, pharmacology and safety in the perspective of traditional uses and recent popularity. Planta Med. 76: 7-19.

Pulido, R., L. Bravo and F. Saura-Calixto. 2000. Antioxidant of dietary polyphenols as determined by a modified ferric reducing antioxidant power assay. J. Agric. Food Chem. 46: 3396-3402.
Re, R., N. Pellegrini, A. Proteggemnte, A. Pannala, M. Yang and C. Rice-Evans. 1999. Antioxidant activity applying and improved ABTS radical cation decolorization assay. Free Radic. Biol. Med. 26: $1234-1237$

Ribeiro, S. M. R., J. H. Queiroz, M. E. L. R. de Queiroz, F. M. Campos and H. M. P. Sant'Ana. 2007. Antioxidant in mango (Mangifera indica L.) pulp. Plant Foods Hum. Nutr. 62: 13-17.

Rodrigues, E., N. Poerner, I. I. Rockenbach, L. V. Gonzaga, C. R. Mendes and R. Fett. 2011. Phenolic compounds and antioxidant activity of blueberry cultivars grown in Brazil. Food Sci. Technol. 31: 911-917.

Santos, G. M., G. A. Maia, P. H. M. de Souza, J. M. C. da Costa, R. W. de Figueiredo and G. M. Prado. 2008. Correlation between antioxidant activity and bioactive compounds of açai (Euterpe oleracea Mart) comercial pulps. Arch. Latinoam. Nutr. 58: 187-192.

Shen, X., X. Sun, Q. Xie, H. Liu, Y. Zhao, Y. Pan, C. Hwang and V. C. H. Wu. 2014. Antimicrobial effect of blueberry (Vaccinium corymbosum L.) extracts against the growth of Listeria monocytogenes and Salmonella enteritidis. Food Control. 35: 159-165.

Silva, L. M. R., E. A. T. de Figueiredo, N. M. P. S. Ricardo, I. G. Vieira, R. W. de Figueiredo, I. M. Brasil and C. L. Gomes. 2014 Quantification of bioactive compounds in pulps and by-products of tropical fruits from Brazil. Food Chem. 143: 398-404.

Singleton, V. L., R. Orthofer and R. M. Lamuela-Raventós. 1999. Analysis of total phenols and other oxidation substrates and antioxidants by means of folin-ciocalteu reagent. Method. Enzymol. 299: 152-178.

Souza, V. R., P. A. P. Pereira, T. L. T. da Silva, L. C. O. Lima, R. Pio and F. Queiroz. 2014. Determination of the bioactive compounds, antioxidant activity and chemical composition of brazilian blackberry, red raspberry, strawberry, blueberry and sweet cherry fruits. Food Chem. 156: 362-368.

Su, M. S. and P. J Chien. 2007. Antioxidant activity, anthocyanins, and phenolics of rabbiteye blueberry (Vaccinium ashei) fluid products as affected by fermentation. Food Chem. 104: 182-187.

Swieca, M. 2015. Potentially bioaccessible phenolics, antioxidant activity and nutritional quality of young buckwheat sprouts affected by elicitation and elicitation supported by phenylpropanoid pathway precursor feeding. Food Chem. 192: 625-632.

Valdivielso, I., M. Á. Bustamante, J. C. R. Gordoa, A. I. Nájera, M. Renobales and L. J. R. Barron. 2015. Simultaneous analysis of carotenoids and tocopherols in botanical species using one step solid-liquid extraction followed by high performance liquid chromatography. Food Chem. 173: 709-717.

Wang, C. C., S. C. Chang, B. S. Inbaraj and B. H. Chen. 2010 Isolation of carotenoids, flavonoids and polysaccharides from Lycium barbarum $\mathrm{L}$. and evaluation of antioxidant activity. Food Chem. 120: 184-192.

Wang, X., J. Zhang and I. E. Cock. 2016. Açai, cacao and maça extracts: Anticancer activity and growth inhibition of microbial triggers of selected autoimmune inflammatory diseases. Pharmacogn. Commn. 6: 204-214.

Wawruszak, A., A. Czerwonka, K. Okła and W. Rzeski. 2016 Anticancer effect of ethanol Lycium barbarum (Goji berry) extract on human breast cancer T47D cell line. Nat. Prod. Res. 30: 1993-1996.

Yuyama, L. K. O., J. P. L. Aguiar, D. F. S. Filho, K. Yuyama, M. J. Varejão, D. I. T. Fávaro, M. B. A. Vasconcellos, S. A. Pimentel and M. S. F. Caruso. 2011. Physicochemical characterization of açai juice of Euterpe precatoria Mart. from different amazonian ecosystems. Acta Amazon. 41: 545-552. 